\title{
Review \\ Role of RANKL inhibition in osteoporosis
}

\author{
Michael McClung
}

Oregon Osteoporosis Center, NE Hoyt Street, Portland, Oregon 97213, USA

Corresponding author: Michael McClung, mmcclung@orost.com

Published: 29 June 2007

This article is online at http://arthritis-research.com/content/9/S1/S3

(C) 2007 BioMed Central Ltd
Arthritis Research \& Therapy 2007, 9(Suppl 1):S3 (doi:10.1186/ar2167)

about 20\% [3]. One-third of hip fractures occur in men. A healthy 50 -year-old woman has a $40 \%$ to $50 \%$ chance of experiencing an osteoporosis-related fracture over the remainder of her lifetime, whereas approximately $20 \%$ of men will experience fragility fractures.

Caring for patients with these fractures is expensive; the annual direct care expenditure on caring for patients with osteoporotic fractures was US\$12 to 18 billion in 2002 [3]. The incidence of fractures increases progressively with advancing age. Furthermore, as the global population grows older, the number of fractures is expected to double or triple by the year 2050, resulting in increased costs both to individuals and to society [6].

\section{Pathophysiology of bone loss and fractures}

Bone mass accumulates during the first two decades of life. In healthy persons, peak bone mass is influenced primarily by genetic factors and body size [7]. Illnesses or nutritional deficiency during childhood and reduced exposure to sex steroids during adolescence often blunt the acquisition of peak bone mass, predisposing to osteoporosis in later life.

After the completion of skeletal growth, bone health is maintained by the coupled processes of bone resorption and bone formation, together called bone remodeling [8]. Old or damaged bone is removed and replaced by healthy bone. In young adults these processes are balanced, and skeletal renewal occurs without significant change in bone mass. Various diseases, drugs, and metabolic abnormalities adversely affect bone health and contribute to the development of osteoporosis. Activation of osteoclastic bone resorption is a common factor in the pathogenesis of bone loss and fractures [9]. Estrogen deficiency at menopause or androgen deficiency in men results in an unbalanced increase in bone turnover, such that bone resorption exceeds bone formation. Relatively rapid bone loss occurs and is accompanied by destruction of bone microarchitecture [10]. In older

$\mathrm{BMD}=$ bone mineral density; BSAP = bone-specific alkaline phosphatase; CTX = C-telopeptide; NTX = N-telopeptide; OPG = osteoprotegerin; $\mathrm{RANK}=$ receptor activator of nuclear factor- $\mathrm{KB} ; \mathrm{RANKL}=$ receptor activator of nuclear factor- $\mathrm{\kappa} B$ ligand. 
adults vitamin D deficiency is common; it impairs calcium absorption and induces secondary hyperparathyroidism, in turn resulting in bone loss and increased fracture risk [11].

Low bone mineral density (BMD) is an important risk factor for fractures. For every standard deviation decrease in ageadjusted BMD, the relative risk for fracture increases by 1.5 fold to 2.5-fold [12]. The relationship between BMD and fracture risk is strongly modulated by age and other clinical risk factors such as prior fracture history, lifestyle factors, and frailty [13]. Estimates of fracture probability, made by combining bone density and clinical risk factors, can be used to identify patients for whom therapy would be appropriate.

\section{Treatment of osteoporosis}

The primary objective of treating patients with or who are at risk for osteoporosis is to reduce the likelihood of new fractures, and effective therapies exist. The use of calcium and vitamin D supplements in older adults and hip protectors in fall-prone elderly patients have been shown to reduce fracture risk $[14,15]$. However, bone-strengthening osteoporosis drugs are the most effective therapies. The antiresorptive (anticatabolic) drugs estrogen, raloxifene, and bisphosphonates effectively prevent bone loss in postmenopausal women without osteoporosis [16-18]. Treatment with either an antiresorptive drug or teriparatide, an anabolic agent, preserves or improves bone mass and substantially reduces fracture risk in postmenopausal women and men with osteoporosis [19]. In the clinical trial setting, bisphosphonates, raloxifene, and teriparatide reduced the incidence of new vertebral fractures by about $50 \%$ and the incidence of multiple spine fractures by $75 \%$ to $95 \%$ [20-23]. Bisphosphonates and teriparatide reduce the incidence of nonvertebral fracture, and both alendronate and risedronate decrease the incidence of hip fracture in postmenopausal women with osteoporosis by about 50\% [20,24]. The potential to achieve additive effects by combining a potent antiresorptive agent such as alendronate with a bone-forming drug such as teriparatide has not yet been realized $[25,26]$. The anabolic effects of teriparatide, assessed by changes in bone density, biochemical indices of bone turnover, and bone histomorphometry, were blunted when the agent was administered concurrently with alendronate.

In general these therapies are well tolerated. The effectiveness of treatment in clinical practice is limited by real or perceived intolerance, and especially by poor adherence to therapy, because most patients discontinue treatment before the end of the first year $[27,28]$.

\section{Rationale for RANKL inhibitors to treat osteoporosis}

Receptor activator of nuclear factor- $\kappa B$ (RANK) is a member of the tumor necrosis factor family expressed by osteoclasts and their precursors [29]. The interaction of RANK with its ligand (RANKL) has been identified as the final common pathway through which bone resorption is regulated [29]. By binding to its receptor RANK on osteoclastic precursors, RANKL controls the differentiation, proliferation, and survival of osteoclasts. Osteoprotegerin (OPG) is the natural inhibitor of RANKL. Mice that are deficient in OPG exhibit osteoporosis, whereas over-expression of OPG in mice results in reduced numbers of osteoclasts and high bone mass $[30,31]$. Perturbations in the ratio of OPG to RANKL have been demonstrated to occur with estrogen deficiency, hyperparathyroidism, and other disorders that stimulate bone resorption [32-34]. RANKL is also expressed by lymphocytes and synovial fibroblasts and may mediate bone loss associated with inflammatory conditions $[35,36]$. The discovery of the RANK/RANKL/OPG pathway and its implications in the pathogenesis of osteoporosis provides a molecular target for new therapies to improve bone health. RANK and RANKL are expressed by endothelial cells and lymphocytes, and this pathway may have importance in cardiovascular diseases and immune function [37].

\section{Preclinical studies}

Studies in animals have evaluated the effects of administering recombinant OPG or OPG fused to immunoglobulin Fc fragments (to increase the half-life of OPG). The osteopenia observed in OPG-deficient mice was reversed by injections of the OPG-Fc fusion protein or by introducing the OPG gene using an adenovirus expression vector [38,39]. Postoophorectomy bone loss in rats was prevented or reversed by administration of OPG-Fc fusion protein [40,41]. This treatment quickly and potently inhibited indices of bone resorption, and was associated with normal bone histology and significant improvement in bone strength. OPG therapy prevented bone loss in immobilized rats [42].

A preliminary report by Kostenuik and his colleagues, presented at the European Congress on Clinical and Economic Aspects of Osteoporosis in 2005 [43], described the effects of treating intact female cynomologous monkeys with OPG-Fc for 6 months. Urinary N-telopeptide (NTX), a marker of bone resorption, was reduced by about $90 \%$. This was accompanied by improvements in bone mass in both the trabecular and cortical compartments of the distal radius and proximal tibia, as measured by peripheral quantitative computed tomography. Cortical bone mineral content increased, as compared with the control group, by $269 \%$ in the distal radius and $67 \%$ in the proximal tibia with OPG therapy. Cortical thickness increased by $251 \%$ and $39 \%$ in the radius and tibia, respectively. This increase in cortical thickness was the result of both a decrease in the resorption of the inner surface of the cortex (decreased endosteal circumference of $40 \%$ with treatment) and either enhanced deposition or decreased resorption of bone on the outer surface (increased periosteal circumference of 20\%). As a result of both the increase in bone mineral content and the increase in cortical thickness and diameter, a calculated index of bone strength was increased by $288 \%$ in treated 
compared with control animals. These effects on cortical bone structure are substantially greater than have been observed with other antiresorptive agents.

At the 2006 Meeting of the American Society for Bone and Mineral Research, the same group reported the effects of inhibiting RANKL with an anti-RANKL antibody in estrogendeficient older monkeys [44]. Therapy for up to 16 months prevented loss of cancellous bone and preserved indices of bone strength. Combining OPG therapy with parathyroid hormone resulted in greater increases in BMD and bone strength in rats than was achieved with either treatment alone $[45,46]$.

\section{Clinical experience with RANKL inhibitors Osteoprotegerin}

To evaluate the concept that inhibition of RANKL could have clinical utility, 52 healthy postmenopausal women were given single doses of Fc:OPG of 0.1. 0.3, 1.0, and $3.0 \mathrm{mg} / \mathrm{kg}$ in a phase I, randomized, placebo-controlled study [47]. The women were followed for 84 days to determine the effects of OPG therapy on urinary NTX (a specific marker of bone resorption) and bone-specific alkaline phosphatase (BSAP; an index of bone formation). Within 12 hours, a dosedependent decrease in NTX/creatinine ratio was observed. Decreases of $70 \%$ to $80 \%$ occurred within 5 days with the highest doses. NTX/creatinine values returned to baseline within several weeks. Significant decreases in BSAP levels were observed with the two higher doses. Inhibition of BSAP occurred more slowly, reaching a nadir at 60 days in the 3.0 $\mathrm{mg} / \mathrm{kg}$ group of about $30 \%$ below baseline. No serious or severe adverse events were reported. A transient neutralizing antibody to OPG was observed in one patient, without obvious clinical effects.

These data provide evidence that inhibition of RANKL, in this case by its natural inhibitor OPG, can have clinically measurable effects. However, the development of OPG as a therapy for osteoporosis was not pursued because of its potential immunogenicity, because immunologic resistance to OPG could have substantial untoward effects on the skeleton.

\section{Anti-RANKL antibody}

Denosumab (formerly called AMG 162) is a fully human $\lg _{2}$ monoclonal antibody that binds with high affinity to human RANKL and blocks binding of RANKL to RANK [48]. Compared with OPG, denosumab binds RANKL more specifically (it is less likely to affect the immune and other regulatory systems), it does not have the potential for autoimmunization against a vital regulatory protein, and it has a longer half-life, which permits less frequent dosing [48]. Each of these attributes makes denosumab a more attractive therapeutic agent than forms of OPG.

Single doses of denosumab ranging from 0.01 to $3.0 \mathrm{mg} / \mathrm{kg}$ were administered by subcutaneous injection to 49 healthy postmenopausal women in a phase I study conducted to evaluate safety, pharmacokinetics, and effects on bone resorption [48]. Pharmacokinetics were nonlinear with dose. A prolonged absorption phase occurred, with maximum serum concentrations being reached between 5 and 21 days after dosing. Disappearance from serum occurred in two phases: a slow phase with half-life ranging from about 20 days at lower doses to about 32 days at higher doses. Below circulating levels of about $1,000 \mathrm{ng} / \mathrm{ml}$, denosumab disappeared more rapidly. Urinary NTX levels were reduced within 12 hours of dosing. The magnitude of the initial response differed only modestly among the doses, but the duration of the effect was dose related, as predicted from the pharmacokinetic data. With a dose of $1 \mathrm{mg} / \mathrm{kg}$ (approximately $60 \mathrm{mg}$ in an average size woman), inhibition of bone resorption was sustained for at least 6 months. A return of NTX levels toward baseline was observed with all of the doses by the end of the 9-month follow-up period. Serum levels of BSAP remained stable for the first 2 weeks and then decreased in a dose-dependent manner, suggesting that the effect on bone formation is an indirect effect. The drug appeared to be well tolerated, with two mild injection site reactions reported. No changes were noted in circulating numbers of white blood cells, $\mathrm{T}$ or B lymphocytes, immunoglobulins, or coagulation factors.

Encouraged by these results, 412 postmenopausal women with low BMD were enrolled in a phase II, randomized, doubleblind, placebo-controlled, dose-ranging trial conducted to determine the effect of denosumab on lumbar spine BMD [49]. The women received subcutaneous injections of placebo or denosumab doses of 6,14 , or $30 \mathrm{mg}$ every 3 months, or $14,60,100$, or $210 \mathrm{mg}$ every 6 months. A separate group was randomly assigned to receive open-label oral alendronate $70 \mathrm{mg}$ once weekly. Treatment groups included 41 to 54 women. All women received calcium $1000 \mathrm{mg}$ and vitamin D 400 IU daily. The study was planned to last for 2 years, with the primary analysis scheduled after 12 months.

After 12 months, BMD in the lumbar spine, measured by dual-energy X-ray absorptiometry, increased similarly in all treatment groups except for the group receiving the smallest 6-monthly dose of denosumab (14 mg) [49]. The average increase was $4.6 \%$ in women who received denosumab $60 \mathrm{mg}$ every 6 months or alendronate, as compared with a decrease of $0.8 \%$ in the placebo group $(P<0.0001$ versus placebo; Figure 1). BMD responses in regions of the proximal femur and total body were at least as great with all but the lowest dose of denosumab compared with alendronate. In the distal radius, a modest increase in BMD occurred with denosumab at $60 \mathrm{mg}$ every 6 months (1.3\%), whereas values decreased by $0.5 \%$ with alendronate and by $2 \%$ in the placebo group (Figure 1).

Biochemical indices of bone resorption (serum C-telopeptide [CTX] and urinary NTX) and bone formation (BSAP) were 
Figure 1

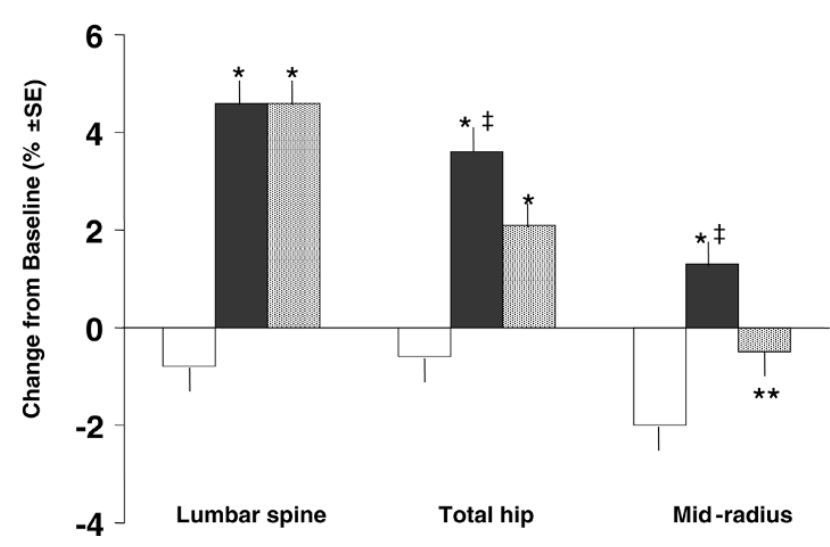

Changes in bone mineral density with denosumab, alendronate, and placebo. Shown here are mean percentage changes from baseline at 12 months in bone mineral density at the lumbar spine, total hip region, and distal third of the radius in women who received placebo (open bars), denosumab $60 \mathrm{mg}$ every 6 months (solid bars), and alendronate $70 \mathrm{mg}$ once weekly (stippled bars) [46]. * $P<0.001$ versus placebo; ${ }^{* *} P<0.05$ versus placebo; ${ }^{*}$ nominal $P<0.01$ versus alendronate. SE, standard error.

measured at 3 days and at monthly intervals after the initial dose [49]. At 3 days, median levels of serum CTX were reduced by $68 \%$ to $83 \%$, and urinary NTX fell by $48 \%$ to $61 \%$ from baseline values in the denosumab treatment groups. Resorption marker values approached or had reached their nadir at 1 month. At this time, CTX values had decreased from baseline by $85 \%$ to $88 \%$ with all doses of denosumab, by $62 \%$ with alendronate, and by $4 \%$ in the placebo group. No differences were noted in initial response between denosumab doses, but the duration of inhibition of bone resorption was dose dependent; larger doses induced longer responses than did smaller doses. At least partial reversal of inhibition of bone resorption was observed with all but the largest dose of denosumab before the second doses were administered at 3 or 6 months. Similar responses of bone resorption markers were observed with subsequent dosing. Serum BSAP levels did not change during the first month after dosing, and then gradually decreased in all treatment groups to about $60 \%$ below baseline values. No differences were observed in the magnitude or timing of BSAP responses among the groups receiving denosumab and that receiving alendronate.

A transient decrease in serum calcium and a concomitant rise in serum parathyroid hormone typically occurs within the first few weeks after administration of a potent anti-resorptive agent. This was observed both in the groups receiving denosumab and in those receiving alendronate [49]. In six women who received denosumab (1.9\%), the albuminadjusted serum calcium value fell below the reference range. None of the women experienced symptoms of hypocalcemia, and values spontaneously returned to the normal range.
Denosumab was well tolerated [49]. The frequency of adverse experiences was similar among all treatment groups, and there was no evidence of a dose-response effect of denosumab for any set of adverse experiences. Two mild and transient injection site reactions occurred. Because RANKL is expressed in lymphocytes, special attention was given to evaluation of immune function. No clinical or laboratory evidence of an adverse effect on the immune system was noted. Two women developed transient non-neutralizing antidenosumab antibodies. In neither woman did the antibody appear to alter therapeutic effectiveness. Unlike the potential for skeletal harm with anti-OPG antibodies, immunologic resistance to denosumab would not adversely affect the skeleton but would simply render the drug ineffective.

Preliminary results of the second year of this study were presented at the 6th European Congress on Clinical and Economic Aspects of Osteoporosis and Osteoarthritis in March 2006 [50]. Therapeutic effectiveness persisted. Increases in BMD were maintained or improved. The patterns of inhibition of bone resorption markers following doses administered during the second year were identical to those observed during the first year. No tolerability or safety concerns were identified during the second year.

Extensions of the phase II study will evaluate safety for longer treatment periods and will provide information about the extent of reversibility following discontinuation of treatment. Doses of $30 \mathrm{mg}$ every 3 months and $60 \mathrm{mg}$ every 6 months appeared be the best suited for clinical use. Because of the potential to improve long-term adherence to therapy with less frequent dosing, $60 \mathrm{mg}$ every 6 months has been selected for further development for the treatment of osteoporosis. Phase III studies are underway to evaluate the effectiveness of denosumab in reducing fracture risk in postmenopausal women with osteoporosis and in preventing bone loss in women without osteoporosis. These studies are substantially larger than the phase II study and will provide much more information about the safety and tolerability of denosumab. Additional studies will determine the effectiveness of denosumab in treating patients with osteoporosis induced by drug treatment, including glucocorticoid therapy, aromatase inhibitors (in women with breast cancer), and inhibitors of gonadotropin secretion (in men with prostate cancer).

\section{Conclusion}

Inhibiting RANKL with a highly specific antibody significantly affects bone metabolism and appears to be a promising treatment for osteoporosis and other bone diseases characterized by increased bone turnover. In addition to documenting and quantifying the efficacy of denosumab therapy in large numbers of patients, it will be important to monitor potential effects on the cardiovascular and immune systems.

\section{Competing interests}

MM receives research grants and consulting fees from Amgen, Lilly, Merck, Novartis, Procter \& Gamble, Roche, and Sanofi-Aventis. 


\section{Acknowledgements}

I thank Ms Joyce Allnutt for secretarial and editorial assistance.

This article is published as part of Arthritis Research \& Therapy Volume 9 Supplement 1, 2007: Basic science, rationale, background and future of denosumab: a RANK ligand inhibitor. The full contents of the supplement are available online at http://arthritis-research.com/supplements/9/S1.

Publication of the supplement has been supported by an unrestricted grant from Amgen Inc.

\section{References}

1. NIH Consensus Development Panel on Osteoporosis Prevention, Diagnosis, and Therapy: Osteoporosis prevention, diagnosis, and therapy. JAMA 2001, 285:785-795.

2. Johnell O, Kanis JA, Oden A, Sernbo I, Redlund-Johnell I, Petterson C, De Laet C, Jonsson B: Mortality after osteoporotic fractures. Osteoporos Int 2004, 15:38-42.

3. US Department of Health and Human Services: Bone Health and Osteoporosis: A Report of the Surgeon General. Washington, DC: Public Health Service, Office of the Surgeon General; 2004.

4. Silverman SL: The clinical consequences of vertebral compression fracture. Bone 1992, Suppl 2:S21-S31.

5. Johnell O, Kanis JA, Oden A, Sernbo I, Redlund-Johnell I, Petterson C, De Laet C, Jonsson B: Fracture risk following an osteoporotic fracture. Osteoporos Int 2004, 15:175-179.

6. Gullberg B, Johnell O, Kanis JA: World-wide projections for hip fracture. Osteoporos Int 1997, 7:407-413.

7. Heaney RP, Abrams S, Dawson-Hughes B, Looker A, Marcus R, Matkovic V, Weaver C: Peak bone mass. Osteoporos Int 2000, 11:985-1009.

8. Raisz LG: Pathogenesis of osteoporosis: concepts, conflicts, and prospects. J Clin Invest 2005, 115:3318-3325.

9. Robbins JA, Schott AM, Garnero P, Delmas PD, Hans D, Meunier PJ: Risk factors for hip fracture in women with high BMD: EPIDOS study. Osteoporos Int 2005, 16:149-154.

10. Dufresne TE, Chmielewski PA, Manhart MD, Johnson TD, Borah $B$ : Risedronate preserves bone architecture in early postmenopausal women in 1 year as measured by three-dimensional microcomputed tomography. Calcif Tissue Int 2003, 73: 423-432.

11. Lips P: Vitamin D deficiency and secondary hyperparathyroidism in the elderly: consequences for bone loss and fractures and therapeutic implications. Endocr Rev 2001, 22:477-501.

12. Marshall $D$, Johnell $O$, Wedel $H$ : Meta-analysis of how well measures of bone mineral density predict occurrence of osteoporotic fractures. BMJ 1996, 312:1254-1259.

13. Kanis JA: Diagnosis of osteoporosis and assessment of fracture risk. Lancet 2002, 359:1929-1936.

14. Bischoff-Ferrari HA, Willett WC, Wong JB, Giovannucci E, Dietrich $T$, Dawson-Hughes B: Fracture prevention with vitamin D supplementation: a meta-analysis of randomized controlled trials. JAMA 2005, 293:2257-2264.

15. Kannus $P$, Parkkari J, Niemi S, Pasanen M, Palvanen M, Järvinen $M$, Vuori I: Prevention of hip fracture in elderly people with use of a hip protector. N Engl J Med 2000, 343:1506-1513.

16. The Writing Group for the PEPI: Effects of hormone therapy on bone mineral density: results from the Postmenopausal Estrogen/Progestin Interventions (PEPI) trial. JAMA 1996, 276:1389-1396.

17. Delmas PD, Bjarnason NH, Mitlak BH, Ravoux AC, Shah AS, Huster WJ, Draper M, Christiansen C: Effects of raloxifene on bone mineral density, serum cholesterol concentrations, and uterine endometrium in postmenopausal women. $N$ Engl $J$ Med 1997, 337:1641-1647.

18. McClung MR, Wasnich RD, Hosking DJ, Christiansen C, Ravn P, Wu M, Mantz AM, Yates J, Ross PD, Santora AC: Prevention of postmenopausal bone loss: six-year results from the early postmenopausal intervention cohort. J Clin Endocrinol Metab 2004, 89:4879-4885.

19. Delmas PD: Treatment of postmenopausal osteoporosis. Lancet 2002, 359:2018-2026.

20. Black DM, Cummings SR, Karpf DB, Cauley JA, Thompson DE, Nevitt MC, Bauer DC, Genant HK, Haskell WL, Marcus R, et al:: Randomised trial of effect of alendronate on risk of fracture in women with existing vertebral fractures. Fracture Intervention Trial Research Group. Lancet 1996, 348:1535-1541.

21. Ettinger B, Black DM, Mitlak BH, Knickerbocker RK, Nickelsen $T$, Genant HK, Christiansen C, Delmas PD, Zanchetta JR, Stakkestad J, et al.: Reduction of vertebral fracture risk in postmenopausal women with osteoporosis treated with raloxifene: results from a 3-year randomized clinical trial. Multiple Outcomes of Raloxifene Evaluation (MORE) Investigators. JAMA 1999, 282:637-645.

22. Harris ST, Watts NB, Genant HK, McKeever CD, Hangartner T, Keller M, Chesnut CH III, Brown J, Eriksen EF, Hoseyni MS, et al.: Effects of risedronate treatment on vertebral and nonvertebral fractures in women with postmenopausal osteoporosis: a randomized controlled trial. Vertebral Efficacy With Risedronate Therapy (VERT) Study Group. JAMA 1999, 282:13441352.

23. Neer RM, Arnaud CD, Zanchetta JR, Prince R, Gaich GA, Reginster JY, Hodsman AB, Eriksen EF, Ish-Shalom S, Genant HK, et al.: Effect of parathyroid hormone (1-34) on fractures and bone mineral density in postmenopausal women with osteoporosis. N Engl J Med 2001, 344:1434-1441.

24. McClung MR, Geusens P, Miller PD, Zippel H, Bensen WG, Roux C, Adami S, Fogelman I, Diamond T, Eastell R, et al.: Effect of risedronate on the risk of hip fracture in elderly women. $N$ Engl J Med 2001, 344:333-340.

25. Black DM, Greenspan SL, Ensrud KE, Palermo L, McGowan JA, Lang TF, Garnero P, Bouxsein ML, Bilezikian JP, Rosen CJ: The effects of parathyroid hormone and alendronate alone or in combination in postmenopausal osteoporosis. $N$ Engl J Med 2003, 349:1207-1215.

26. Finkelstein JS, Hayes A, Hunzelman JL, Wyland JJ, Lee H, Neer RM: The effects of parathyroid hormone, alendronate, or both in men with osteoporosis. N Engl J Med 2003, 349:1216-1226.

27. Recker RR, Gallagher R, MacCosbe PE: Effect of dosing frequency on bisphosphonate medication adherence in a large longitudinal cohort of women. Mayo Clin Proc 2005, 80:856861.

28. Caro JJ, Ishak KJ, Huybrechts KF, Raggio G, Naujoks C: The impact of compliance with osteoporosis therapy on fracture rates in actual practice. Osteoporos Int 2004, 15:1003-1008.

29. Hofbauer LC, Khosla S, Dunstan CR, Lacey DL, Boyle WJ, Riggs $\mathrm{BL}$ : The roles of osteoprotegerin and osteoprotegerin ligand in the paracrine regulation of bone resorption. $J$ Bone Miner Res 2000, 15:2-12.

30. Bucay N, Sarosi I, Dunstan CR, Morony S, Tarpley J, Capparelli C, Scully S, Tan HL, Xu W, Lacey DL, et al.: Osteoprotegerin-deficient mice develop early onset osteoporosis and arterial calcification. Gene Dev 1998, 12:1260-1268.

31. Simonet WS, Lacey DL, Dunstan CR, Kelley M, Chang MS, Luthy $\mathrm{R}$, Nguyen HQ, Wooden S, Bennett L, Boone T, et al:: Osteoprotegerin: a novel secreted protein involved in the regulation of bone density. Cell 1997, 89:309-319.

32. Hofbauer LC, Khosla S, Dunstan CR, Lacey DL, Spelsberg TC, Riggs BL: Estrogen stimulates gene expression and protein production of osteoprotegerin in human osteoblastic cells. Endocrinology 1999, 140:4367-4370.

33. Lochlin RM, Khosla S, Turner RT, Riggs BL: Mediators of the bisphasic responses of bone to intermittent and continuously administered parathyroid hormone. J Cell Biochem 2003, 89: 180-190.

34. Hofbauer LC, Gori F, Riggs BL, Lacey DL, Dunstan CR, Spelsberg TC, Khosla S: Stimulation of osteoprotegerin ligand and inhibition of osteoprotegerin production by glucocorticoids in human osteoblastic lineage cells. Endocrinology 1999, 140: 4382-4389.

35. Kong YY, Feige U, Sarosi I, Bolon B, Tafuri A, Morony Capparelli $\mathrm{C}, \mathrm{Li}$ J, Elliott R, McCabe S, Wong T, et al.: Activated T cells regulate bone loss and joint destruction in adjuvant arthritis through Osteoprotegerin ligand. Nature 1999, 402:304-309.

36. Takayanagi $H$, lizuka H, Juji T, Nakagawa T, Yamamoto A, Miyazaki T, Koshihara Y, Oda H, Nakamura K, Tanaka S: Involvement of receptor activator of nuclear factor kappaB ligand/osteoclast differentiation factor in osteoclastogenesis from synoviocytes in rheumatoid arthritis. Arthritis Rheum 2000, 43:259-269.

37. Collin-Osdoby $\mathrm{P}$, Rothe L, Anderson F, Nelson M, Maloney W, Osdoby P: Receptor activator of NF-kappa B and osteoprotegerin expression by human microvascular endothelial cells, 
regulation by inflammatory cytokines, and role in human osteoclastogenesis. J Biol Chem 2001, 276:20659-20672.

38. Min H, Morony S, Sarosi I, Dunstan CR, Capparelli C, Scully S, Van G, Kaufman S, Kostenuik PJ, Lacey DL, et al:: Osteoprotegerin reverses osteoporosis by inhibiting endosteal osteoclasts and prevents vascular calcification by blocking a process resembling osteoclastogenesis. J Exp Med 2000, 192:463-474.

39. Bolon B, Carter C, Daris M, Morony S, Capparelli C, Hsieh A, Mao M, Kostenuik P, Dunstan CR, Lacey DL, Sheng JZ: Adenoviral delivery of osteoprotegerin ameliorates bone resorption in a mouse ovariectomy model of osteoporosis. Mol Ther 2001, 3: 197-205.

40. Capparelli C, Morony S, Warmington K, Adamu S, Lacey D, Dunstan CR, Stouch B, Martin S, Kostenuik PJ: Sustained antiresorptive effects after a single treatment with human recombinant osteoprotegerin (OPG): a pharmacodynamic and pharmacokinetic analysis in rats. J Bone Miner Res 2003, 18: 852-858.

41. Shimizu-Ishiura M, Kawana F, Sasaki T: Osteoprotegerin administration reduces femural bone loss in ovariectomized mice via impairment of osteoclast structure and function. $J$ Electron Microsc 2002, 51:315-325.

42. Bateman TA, Dunstan CR, Ferguson VL, Lacey DL, Ayers RA, Simske SJ: Osteoprotegerin mitigates tail suspension-induced osteopenia. Bone 2000, 26:443-449.

43. Kostenuik PJ, Ominsky MS, Cramner P, Atkinson J: The RANKL antagonist OPG-Fc causes significant increases in cortical bone thickness, density, and bone strength index in adult female cynomologus monkeys. Osteoporos Int 2005, Suppl 3: S68.

44. Atkinson J, Cranmer $P$, Saunders $T$, Niehaus $M$, Smith SY, Varela A, Ominsky MS, Cosenza ME, Kostenuik PJ: AMG 162, a fully human RANKL antibody, increases bone mass and bone strength in cynomolgus monkeys. J Bone Miner Res 2005, 20: S29.

45. Kostenuik PJ, Capparelli C, Morony S, Adamu S, Shimamoto G, Shen V, Lacey DL, Dunstan CR: OPG and PTH-(1-34) have additive effects on bone density and mechanical strength in osteopenic ovariectomized rats. Endocrinology 2001, 142: 4295-4304.

46. Valenta A, Roschger P, Fratzl-Zelman N, Kostenuik PJ, Dunstan CR, Fratzl P, Klaushofer K: Combined treatment with PTH (1-34) and OPG increases bone volume and uniformity of mineralization in aged ovariectomized rats. Bone 2005, 37:8795.

47. Bekker PJ, Holloway D, Nakanishi A, Arrighi M, Leese PT, Dunstan CR: The effect of a single dose of osteoprotegerin in postmenopausal women. J Bone Miner Res 2001, 16:348-360.

48. Bekker PJ, Holloway DL, Rasmussen AS, Murphy R, Martin SW, Leese PT, Holmes GB, Dunstan CR, DePaoli AM: A single-dose placebo-controlled study of AMG 162 , a fully human monoclonal antibody to RANKL, in postmenopausal women. J Bone Miner Res 2004, 19:1059-1066.

49. McClung MR, Lewiecki EM, Cohen SB, Bolognese MA, Woodson GC, Moffett AH, Peacock M, Miller PD, Lederman SN, Chesnut $\mathrm{CH}$, et al.: Denosumab in postmenopausal women with low bone mineral density. N Engl J Med 2006, 354:821-831.

50. Lewiecki EM, Miller PD, McClung MR, Cohen SB, Liu Y, Wang A, Fitzpatrick LA: Denosumab (AMG 162) inhibition of RANK ligand increases bone mineral density in postmenopausal osteoporosis women after two years of treatment. Osteoporos Int 2006, Suppl 2:S4. 